Ciência Florestal, Santa Maria, v. 24, n. 3, p. 699-706, jul.-set., 2014

ISSN 0103-9954

\title{
CARACTERIZAÇÃO DO MATERIAL COMBUSTÍVEL SUPERFICIAL NO PARQUE NACIONAL SERRA DE ITABAIANA - SERGIPE, BRASIL
}

\author{
CHARACTERIZATION OF THE UNDERSTORY FUEL IN 'SERRA DE ITABAIANA' NATIONAL \\ PARK - SERGIPE STATE, BRAZIL
}

\author{
Benjamin Leonardo Alves White ${ }^{1}$ Adauto de Souza Ribeiro ${ }^{2}$ Larissa Alves Secundo White ${ }^{3}$ Genésio \\ Tâmara Ribeiro ${ }^{4}$
}

\section{RESUMO}

O Parque Nacional Serra de Itabaiana, assim como diversas outras unidades de conservação no Brasil, comumente sofrem perdas ecológicas em função dos incêndios que os atingem. Sendo assim, torna-se essencial compreender as características do material combustível para um melhor entendimento do comportamento do fogo e como melhor combatê-lo. Para tal, foram demarcadas 108 parcelas de $1 \mathrm{~m}^{2}$ onde todo o material combustível superficial foi coletado e pesado. Subamostras foram retiradas e colocadas na estufa para determinar o teor de umidade e o peso da matéria seca. No total, foram coletados, dentro da área de estudo, 91,38 kg de biomassa seca, correspondente a 8,46 t/ha. Considerando cada fitofisionomia individualmente, os Campos Graminosos apresentaram uma média de 3,7 t/ha de material combustível, as Matas 12,5 t/ha e as Areias Brancas 9,18 t/ha. Os resultados obtidos sugerem maior facilidade de ignição do material combustível nas áreas de Areias Brancas; maior dificuldade de ignição nas áreas de Matas; e incêndios de curta duração nas áreas de Campos Graminosos.

Palavras-chave: incêndios florestais; comportamento do fogo; unidades de conservação.

\begin{abstract}
The National Park 'Serra de Itabaiana', as well as other conservation units in Brazil, has commonly suffered ecological losses caused by the wildfires. It is essential to comprehend the characteristics of the fuel to a better understanding of a forest fire behavior and how to extinguish it. In order to do so, 108 plots of $1 \mathrm{~m}^{2}$ were delimitated and all of the surface fuel was collected and weighed. The samples were then removed and placed in an oven to determine the moisture content and the dry weight. It was collected, in the study area, a total of $91.38 \mathrm{~kg}$ of dry biomass, corresponding to $8.46 \mathrm{t} / \mathrm{ha}$. Considering each vegetation type, the Grass Fields had an average of 3.7t/ha of fuel load, the Forests 12.5t/ha and the White Sands 9.18t/ha. The results suggest that the fuel in white sand areas can ignite more easily; there is greater difficulty of fire ignition in forest areas; and short-lived fires in grass fields.
\end{abstract}

Keywords: forest fire; fire behavior; conservation units.

1 Biólogo, Msc., Doutorando em Desenvolvimento e Meio Ambiente pela Universidade Federal de Sergipe, Laboratório GEOPLAN, Av. Marechal Rondon, s/n, Jardim Rosa Elze, CEP 49100-000, São Cristóvão (SE), Brasil. Bolsista FAPITEC. benjmk@hotmail.com

2 Biólogo, Dr., Professor Associado da Universidade Federal de Sergipe, Av. Marechal Rondon, s/n, Jardim Rosa Elze, CEP 49100-000, São Cristóvão (SE), Brasil. adautosr@ufs.br

3 Engenheira Florestal, Msc., Estagiária no Laboratório de Entomologia da Universidade Federal de Sergipe, Av. Marechal Rondon, s/n, Jardim Rosa Elze, CEP 49100-000, São Cristóvão (SE), Brasil. larissawhite@hotmail.com

4 Engenheiro Florestal, Dr., Professor Adjunto da Universidade Federal de Sergipe, Av. Marechal Rondon, s/n, Jardim Rosa Elze, CEP 49100-000, São Cristóvão (SE), Brasil. genesiotr@hotmail.com

Recebido para publicação em 31/01/2012 e aceito em 18/04/2013

Ci. Fl., v. 24, n. 3, jul.-set., 2014 


\section{INTRODUÇÃO}

Segundo Soares e Batista (2007), incêndio florestal é o termo utilizado para definir um fogo incontrolado que se propaga livremente e consome os diversos tipos de material combustível existentes em uma floresta. Embora ocorram desde que os raios e a vegetação passaram a coexistir na Terra, estudos específicos a respeito do comportamento do fogo começaram a ser desenvolvidos à medida que as florestas nativas e reflorestamentos passaram a ter um valor econômico associado.

Nos reflorestamentos, a alta produtividade e concentração de biomassa representam um grande risco para ocorrência de incêndios florestais de grande porte. Nestas áreas, o fogo costuma ser veementemente temido, já que existe um alto valor econômico associado à venda de madeira. Nas áreas de floresta tropical, o fogo apresenta um risco para a conservação da biodiversidade e de locais com beleza cênica passíveis ao ecoturismo. Levando tais fatos em consideração, é essencial a implementação de eficientes atividades de prevenção e combate a incêndios florestais que busquem a minimização dos danos causados pelo fogo.

Os incêndios florestais não podem ser manejados sem uma compreensão das características básicas do combustível. A quantidade de material combustível, de acordo com Soares (1985), está diretamente relacionada à intensidade de calor liberada pelo fogo; de acordo com Rego e Botelho (1990), a facilidade de ignição e a velocidade de propagação do fogo vão depender, dentre outros fatores, dos tipos de materiais combustíveis presentes para queima; e o conteúdo de umidade do material combustível é a mais importante propriedade que controla a inflamabilidade dos combustíveis (SOARES; BATISTA, 2007). Sendo assim, é essencial compreender o material combustível e como o mesmo pode ser manejado e manipulado, a fim de que sejam possíveis eficientes ações de combate e prevenção aos incêndios florestais.

De acordo com Chandler et al. (1983), o material combustível florestal constitui todo e qualquer tipo de matéria orgânica, viva ou morta, encontrada no ambiente, capaz de entrar em combustão e queimar, sendo que sua quantidade pode variar de centenas de quilos a dezenas de toneladas por hectare, dependendo do tipo, espaçamento e idade da vegetação.

A quantidade de material combustível existente pode ser subdividida em "total" e “disponível". Esta divisão decorre principalmente do fato de que nem todo combustível se encontra disponível para consumo pelo fogo. $\mathrm{O}$ teor de umidade existente no material combustível é o principal fator que determina esta divisão, aliado, segundo Batista (1990), à proporção entre material vivo e morto, ao tamanho das partículas do combustível e à própria continuidade deste material sobre a superfície do terreno. Segundo Rego e Botelho (1990), a disponibilidade do material combustível pode alterar-se segundo a hora, a época do ano, o estrato, o tempo atmosférico, a vegetação e a intensidade do fogo.

Existem modelos matemáticos que descrevem o comportamento do fogo que vêm sendo desenvolvidos desde a década de 40 . O modelo mais aceito, e mais citado na literatura, é o modelo de Richard C. Rothermel (1972). Este modelo constitui uma ferramenta que é utilizada até os dias atuais pelo Departamento de Agricultura Norte Americano (USDA). O sistema proposto por Rothermel serviu de base para o desenvolvimento de diversos programas computacionais como o "Behave" (BURGAN et al., 1984), "BehavePlus" (ANDREWS et al., 2003), e "Farsite" (FINNEY, 1998), que, além de indicar as condições de combustão, oferecem uma previsão do comportamento do fogo, como por exemplo: intensidade do fogo, comprimento das chamas, direção do incêndio, área consumida pelo fogo, energia calorífera, dentre diversas outras variáveis.

O modelo matemático de Rothermel e os programas computacionais desenvolvidos com base neste modelo requerem como variáveis de entrada, os valores relativos à carga do material combustível florestal e seu respectivo teor de umidade, de acordo com as classes de diâmetro. Portanto, o presente trabalho tem como objetivo quantificar e determinar o teor de umidade do material combustível florestal de acordo com as classes de diâmetro dentro das principais fitofisionomias do Parque Nacional (PARNA) Serra de Itabaiana, para que, futuramente, seja possível a aplicação dos dados obtidos em softwares que analisam o comportamento do fogo.-

\section{MATERIAIS E MÉTODOS}

\section{Caracterização da Área de Estudo}

Aáreadeestudocompreendeasdependências do Parque Nacional Serra de Itabaiana, localizado no estado de Sergipe com elevação máxima de 670 m (Figura 1). O clima, pela classificação de Köppen, 
é tropical com verão seco (As), com precipitações médias anuais de $1200 \mathrm{~mm}$ (DANTAS; RIBEIRO, 2010). Segundo os mesmos autores, existem três formações vegetais predominantes: as formações abertas naturais de Campos Graminosos (3289 ha), principalmente em regiões de relevo acidentado e encostas, compostas por gramíneas altas e densas, sendo principalmente compostas pelas espécies Lagenocarpus rigidus (Kunth.) e Xyris brevifolia (Michx.); as Matas, ou Floresta Tropical sempreverde sazonal sub-montana, (2643 ha) em sua maioria como vegetações secundárias sendo as espécies Campomanesia viatoris (Landrum); Stryphnodendron pulcherrimum (Willd.) e Inga laurina (Sw.) as mais comuns; e o habitat denominado de Areias Brancas, formado por uma vegetação arbustiva mesófila esclerófita em moitas (Ericaceae, Euphorbiaceae, Myrtaceae, Fabaceae e Poligalaceae) algumas vezes associada com uma vegetação herbácea (347 ha).

\section{Coleta do material combustível}

No total foram demarcadas 108 parcelas aleatórias de $1 \times 1 \mathrm{~m}$ dentro das três principais fitofisionomias vegetais classificadas por Dantas e Ribeiro (2010): 36 em áreas de Matas, 36 em áreas de Areias Brancas e 36 em Campos Graminosos. O número de parcelas foi calculado de acordo com a metodologia de amostragem sequencial, com um limite de erro de $10 \%$ a um nível de probabilidade de $95 \%$. O teste Kolmogorov-Smirnov foi aplicado para definir se a quantidade de material combustível em cada formação vegetal apresentou distribuição normal.

A caracterização do material combustível foi realizada durante os meses da estação seca (outubro a maio 2008-2009) através do método de amostragem destrutiva, onde toda a biomassa vegetal até 1,8 $\mathrm{m}$ de altura (limite do material combustível superficial) foi coletada, separada e pesada. A carga do material combustível foi quantificada para as seguintes classes:

A) Material Combustível Vivo:

- Material Herbáceo (MVHerb): Plantas que possuem a consistência e porte de erva. Ex: gramíneas e samambaias.

- Material verde lenhoso (MVL): Incluem a folhagem e os pequenos ramos dos arbustos vivos. São materiais cujo diâmetro é menor ou igual a 0,7 $\mathrm{cm}$.

B) Material Combustível Morto (seco):

- MS1: Material seco com diâmetro menor ou igual a $0,7 \mathrm{~cm}$.

- MS2: Material seco com diâmetro entre 0,71 e 2,5 $\mathrm{cm}$.

- MS3: Material seco com diâmetro entre 2,51 e 7,6 $\mathrm{cm}$.

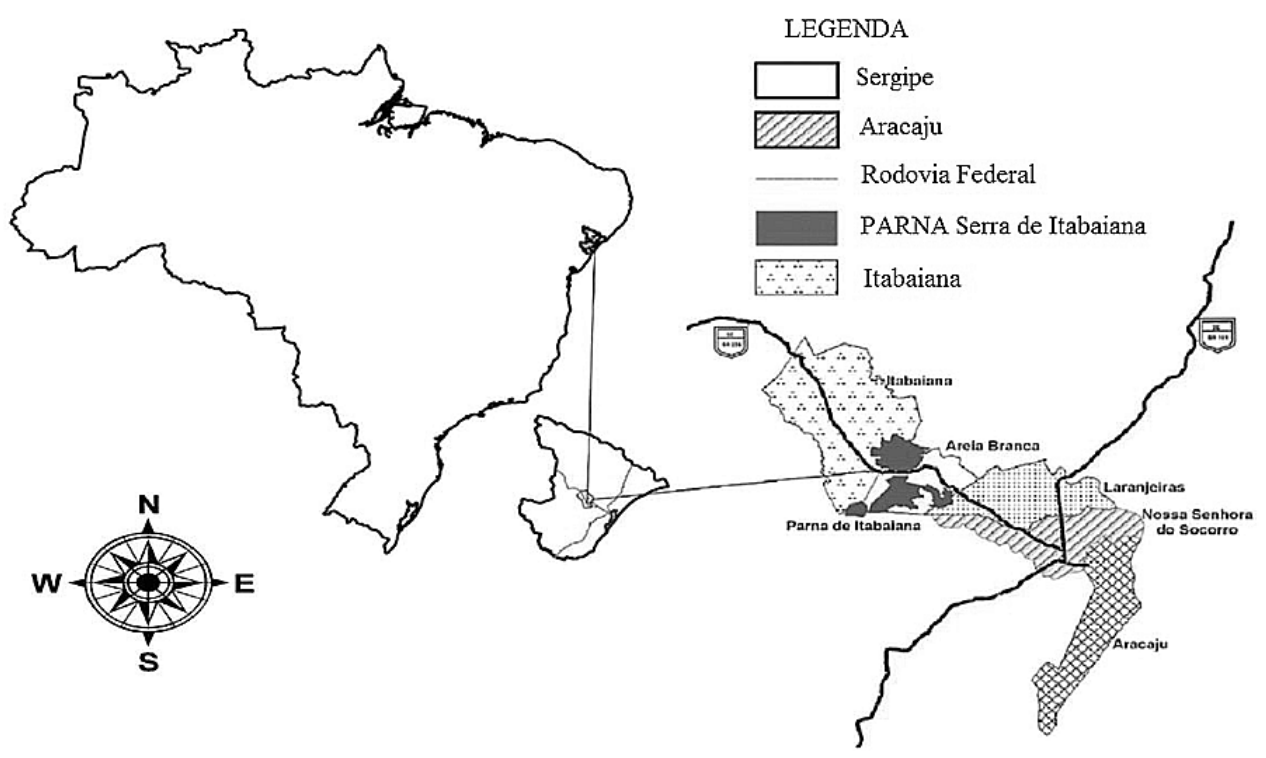

FIGURA 1: Localização do Parque Nacional Serra de Itabaiana - Sergipe (DANTAS; RIBEIRO, 2010). FIGURE 1: Location of the National Park Serra de Itabaiana - Sergipe (DANTAS; RIBEIRO, 2010). 
As metodologias utilizadas para coletar, categorizar e pesar foram baseadas em trabalhos de Rothermel (1972) e Brown et al. (1982). Todo o material combustível morto foi classificado nas classes de diâmetro com auxílio de um paquímetro. Os combustíveis mortos maiores que $7,6 \mathrm{~cm}$ e verdes lenhosos maiores que $0,7 \mathrm{~cm}$ de diâmetro não foram coletados devido a não contribuírem com a propagação do fogo superficial de acordo com o modelo de Rothermel (1972).

Após a operação de coleta, classificação e pesagem, foram retiradas subamostras representativas de cada classe (uma subamostra de cada classe de material combustível dentro de cada parcela) que, depois de pesadas, foram acondicionadas em sacos plásticos e levadas ao laboratório para secagem e posterior determinação do teor de umidade e peso da matéria seca ao forno. A secagem foi feita na estufa, a uma temperatura de $70^{\circ} \mathrm{C}$ até atingir peso constante.

\section{Análise estatística}

Os dados coletados foram inseridos no programa JMP 7.0 onde foram definidos os valores médios, variância e desvio padrão para a carga e umidade de todas as classes de material combustível dentro de cada tipo de vegetação. O teste Kolmogorov-Smirnov foi aplicado para se determinar se a carga de material combustível apresentou distribuição normal dentro de cada vegetação, verificando assim se o número de amostras foi suficiente. Além disso, a análise de variância (ANOVA) foi utilizada com o objetivo de verificar a existência de diferença significativa na carga de material combustível presente dentro de cada tipo de vegetação. A significância utilizada em ambos os casos foi de 5\%.

\section{RESULTADOS E DISCUSSÃO}

Foram coletados ao todo $137,22 \mathrm{~kg}$ de material úmido nas 108 parcelas de $1 \mathrm{~m}^{2}$. Este material apresentou um teor de umidade médio de $33,4 \%$, ou seja, retirando a água, a quantidade total de material combustível seco foi de $91,38 \mathrm{~kg}$, equivalente a 8,46 t/ha. Aplicando-se o teste de Kolmogorov-Smirnov em todas as fitofisionomias,

TABELA 1: Valores Médios, Desvio Padrão e teste Kolmogorov-Smirnov para o material combustível seco presente em cada fitofisionomia no Parque Nacional Serra de Itabaiana, Sergipe, Brasil.

TABLE 1: Median, Stand Error and Kolmogorov-Smirnov test for the dry fuel load inside each phyto-physiognomy at 'Serra de Itabaiana' National Park, Sergipe state, Brazil.

\begin{tabular}{lcc}
\hline \multicolumn{1}{c}{ Fitofisionomia } & Peso médio $(\mathrm{t} / \mathrm{ha})$ & Teste Kolmogorov-Smirnov \\
\hline Campos Graminosos $(\mathrm{n}=36)$ & $3,70( \pm 1,72)$ & $\mathrm{d}=0,164 \mathrm{p}>0,20$ \\
Matas $(\mathrm{n}=36)$ & $12,5( \pm 6,00)$ & $\mathrm{d}=0,165 \mathrm{p}>0,20$ \\
Areias Brancas $(\mathrm{n}=36)$ & $9,18( \pm 4,58)$ & $\mathrm{d}=0,123 \mathrm{p}>0,20$ \\
TOTAL $(\mathrm{n}=108)$ & $8.46( \pm 5,74)$ & \\
\hline
\end{tabular}

Em que: \pm Desvio Padrão.

TABELA 2: Teste ANOVA entre a quantidade de material combustível total dentro de cada fitofisionomias do Parque Nacional Serra de Itabaiana, Sergipe, Brasil.

TABLE 2: ANOVA test between the total amount of fuel load inside each vegetation type from the National Park 'Serra de Itabaiana', Sergipe state, Brazil.

\begin{tabular}{lcc}
\hline \multicolumn{1}{c}{ ANOVA (Carga do Material Combustível) } & $\mathrm{F}$ & $\mathrm{p}$ \\
\hline Matas x Campos Graminosos & 71,48 & $2,66 \times 10^{-12}$ \\
Matas x Areias Brancas & 6,98 & 0,01 \\
Areias Brancas x Campos Graminosos & 45,02 & $4,21 \times 10^{-09}$ \\
Matas x Campos Graminosos x Areias Brancas & 35,54 & $1,63 \times 10^{-12}$ \\
\hline
\end{tabular}

Ci. Fl., v. 24, n. 3, jul.-set., 2014 
determinou-se que os valores relativos à quantidade de material combustível apresentaram distribuição normal (Tabela 1).

Os dados referentes à quantidade de material combustível presente dentro de cada fitofisionomia foram submetidos à análise de variância no qual se verificou que todas as três formações vegetais apresentaram valores significativamente diferentes quando comparados entre si (Tabela 2).

Através da análise da variância pode-se afirmar que na fitofisionomia de matas obtiveram-se os maiores valores relativos à quantidade de material combustível, assim como, os maiores teores de umidade, quando comparados com os das demais fitofisionomias (Tabela 3). Tais resultados se devem ao fato de que uma floresta densa proporciona um microclima mais ameno, a cobertura da copa das árvores impede a entrada de raios solares e diminui a circulação do vento, consequentemente, os combustíveis apresentam um conteúdo de umidade maior e mais estável do que uma floresta rala ou aberta.

Emboraaquantidadedematerialcombustível seja alta nas áreas de mata, comparando com a quantidade presente nas demais fitofisionomias, o seu alto teor de umidade impede que esses materiais entrem em processo de ignição. É necessária uma elevada fonte de energia calorífera para primeiro secar o material para que depois o mesmo possa queimar. Levando-se em consideração que, de acordo com Soares e Batista (2007), os materiais combustíveis com teor de umidade acima de 25 a $30 \%$ possuem remotas possibilidades de ignição, sendo estes os valores atribuídos para caracterizar a umidade de extinção, pode-se concluir que os materiais combustíveis presentes nas áreas de mata dificilmente entrem em processo de combustão.

A fitofisionomia das Areias Brancas apresentou uma quantidade inferior de material combustível quando comparada com as áreas de Mata, entretanto, os materiais combustíveis mortos lá presentes apresentaram os menores teores de umidade (Tabela 3). Levando-se em consideração que, segundo Schroeder (1970), a probabilidade de um material combustível entrar em processo de ignição em uma vegetação depende, acima de tudo, do teor de umidade dos materiais combustíveis mortos de diâmetro inferior a $0,7 \mathrm{~cm}$, pode-se

TABELA 3: Média da carga do material combustível e seu respectivo teor médio de umidade para cada classe dentro de cada fitofisionomia no Parque Nacional Serra de Itabaiana, Sergipe, Brasil.

TABLE 3: Fuel load and humidity content of each category and its respective average content for each class inside each phyto-physiognomy at 'Serra de Itabaiana' National Park, Sergipe state, Brazil.

\begin{tabular}{cccc}
\hline \multirow{2}{*}{ Fitofisionomia } & $\begin{array}{c}\text { Classe do Material } \\
\text { Combustível }\end{array}$ & $\begin{array}{c}\text { Média da Quantidade de Material } \\
\text { Combustível }\end{array}$ & Teor de Umidade Médio \\
\hline \multirow{3}{*}{ Campos Graminosos } & MS1 & $1,36( \pm 0,67) \mathrm{t} / \mathrm{ha}$ & $17,70 \%$ \\
& MS2 & - & - \\
MS3 & - & $44,44 \%$ \\
MVL & $0,21( \pm 0,50) \mathrm{t} / \mathrm{ha}$ & $44,86 \%$ \\
MVtas & MS1 & $2,14( \pm 1,38) \mathrm{t} / \mathrm{ha}$ & $31,82 \%$ \\
& MS2 & $8,14( \pm 3,22) \mathrm{t} / \mathrm{ha}$ & $26,39 \%$ \\
MS3 & $1,79( \pm 1,32) \mathrm{t} / \mathrm{ha}$ & $33,64 \%$ \\
MVL & $2,01( \pm 3,61) \mathrm{t} / \mathrm{ha}$ & $60,21 \%$ \\
MVHeias Brancas & $0,30( \pm 0,38) \mathrm{t} / \mathrm{ha}$ & $50,06 \%$ \\
& MS1 & $0,27( \pm 0,33) \mathrm{t} / \mathrm{ha}$ & $14,41 \%$ \\
& MS2 & $5,54( \pm 2,72) \mathrm{t} / \mathrm{ha}$ & $10,90 \%$ \\
& MS3 & $0,66 \pm 0,91) \mathrm{t} / \mathrm{ha}$ & $6,10 \%$ \\
\hline
\end{tabular}


considerar que, nas áreas onde predominam as fitofisionomias das Areais Brancas, é necessária maior atenção e vigilância por parte das autoridades competentes, pois são nessas áreas onde o material combustível apresenta maior facilidade para entrar em processo de ignição.

Com relação às fitofisionomias de Campos Graminosos, a baixa quantidade de material combustível da classe MS1 e a ausência de materiais nas classes MS2 e MS3 sugere que os incêndios sejam de pequeno porte e queimem rapidamente todo o estoque de material combustível, já que são os materiais mortos mais grossos (MS2 e MS3), responsáveis pelo aumento do tempo de residência do fogo (BATISTA, 1990). Considerando-se que a mínima quantidade de material combustível nos Campos Graminosos necessária para propagar um incêndio florestal está entre 2 a 2,5 t/ha (HÉLY et al., 2003), a variabilidade espacial da carga presente nos Campos Graminosos do Parque Nacional Serra de Itabaiana pode comprometer a propagação do fogo em algumas áreas. Entretanto, a grande maioria das parcelas estudadas (88\%) apresentou carga suficiente $(>2 \mathrm{t} / \mathrm{ha})$ para propagarem incêndios (Figura 2).

Avaliações do material combustível em outras regiões de vegetação natural são importantes, porém, escassos no Brasil. Melo et al. (2006) encontraram média de 11,51 t/ha de material combustível superficial na floresta ombrófila mista e 11,96 t/ha na floresta estacional semidecidual, ambas localizadas no Parque Nacional de Iguaçu Paraná, valor muito próximo ao encontrado nas áreas de Mata no PARNA Serra de Itabaiana. Caldeira
(2003), trabalhando em uma Floresta Ombrófila Mista em General Carneiro - PR, encontrou valores médios de serapilheira variando de 4,43 a $13,71 \mathrm{t}$ / ha.

Mais comuns são estudos realizados em áreas de reflorestamento de monocultura como o de Ribeiro e Soares (1998) que encontraram valores médios de carga de 27 t/ha para o material combustível superficial de uma floresta de Eucalyptus viminalis (Labill) no município de Três Barras - SC. No município de Sacramento - MG, avaliações em floresta de Pinus oocarpa (Schiede), com idade entre 4,5 e 7,5 anos, obtiveram-se cargas de 1,2 a 17,3 t/ha (SOARES, 1979). Em um povoamento de Pinus taeda (L.) com 12 anos de idade, sem abate, no município de Sengés - PR, obteve-se carga média de 12,53 t/ha (BATISTA, 1995). Já Beutling (2005) encontrou cargas entre 10,76 - 20,13 t/ha para florestas de Araucaria angustifolia (Bertol.), no município de Campo Belo do Sul - SC.

\section{CONCLUSÕES}

Dentre as três fitofisionomias analisadas no Parque Nacional Serra de Itabaiana, as Matas apresentaram maior quantidade de material combustível superficial (12,5 t/ha), seguido pelas Areias Brancas $(9,18 \mathrm{t} / \mathrm{ha})$ e pelos Campos Graminosos (3,7 t/ha). O material combustível nas áreas de Matas apresentou os maiores teores de umidade, por vezes maior que a umidade de extinção, portanto, a probabilidade de ignição destes combustíveis é mais baixa, quando

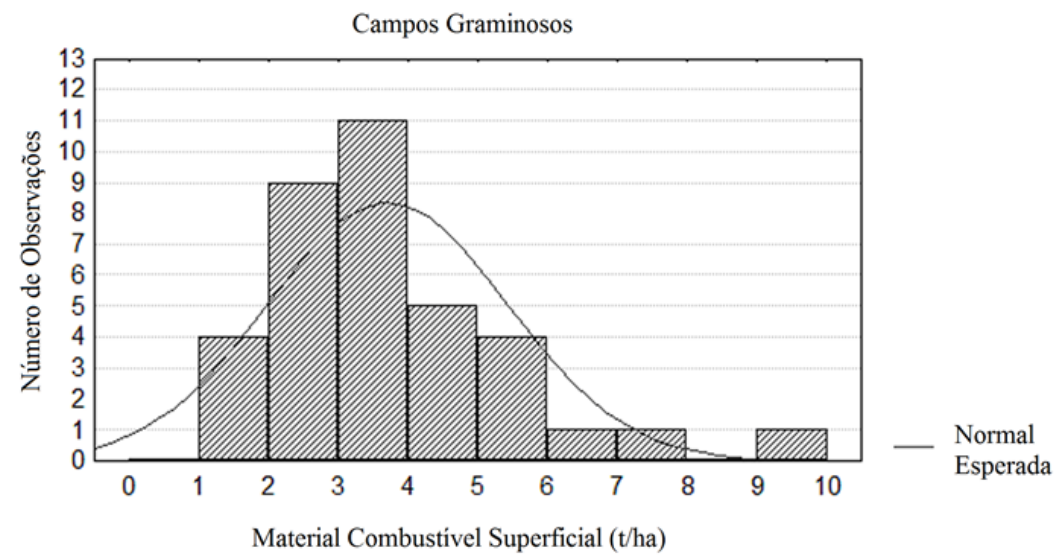

FIGURA 2: Distribuição normal do material combustível superficial nas 36 parcelas dos Campos Graminosos.

FIGURE 2: Normal distribution of the 36 surface fuel load samples inside the Grass Fields. 
comparada com a das outras áreas. As áreas de Areias Brancas apresentaram os menores teores de umidade, portanto, é justificável intensificar o trabalho de prevenção e vigília nestas áreas. Já nos Campos Graminosos, a ausência de combustíveis das Classes MS2 e MS3 sugere que, havendo condições climáticas propícias, os incêndios queimem rapidamente todo o material combustível disponível, sendo o tempo de residência do fogo inferior, quando comparado com outras vegetações.

O presente trabalho constitui o passo inicial na caracterização do comportamento do fogo, de acordo com o modelo matemático desenvolvido por Rothermel. $\mathrm{O}$ passo seguinte a ser tomado será a interligação dos dados obtidos neste trabalho com dados climáticos e de relevo, para que assim seja possível prever as características do incêndio, como por exemplo: intensidade do fogo, altura das chamas, sentido de propagação, área consumida, energia calorífera, dentre outras. A partir desta caracterização será possível o treinamento das forças de combate; a realização de atividades relacionadas com a prevenção das ignições de origem humana; a definição dos níveis de prontidão e do pré-posicionamento dos meios de supressão; o planejamento da intensidade do ataque; o delineamento das tácticas de supressão e da estratégia de combate em incêndios ativos; e o planejamento e execução de queimadas controladas.

\section{AGRADECIMENTOS}

Ao Deutscher Akademischer Austausch Dienst (DAAD) pela bolsa concedida ao primeiro autor.

\section{REFERÊNCIAS BIBLIOGRÁFICAS}

ANDREWS, P. L.; BEVINS, C. D.; SELI, R. C. BehavePlus Fire Modeling System Version 2.0 User's Guide. General Technical Report RMRSGTR-106WWW, USDA Forest Service, Ogden, 2003. 133 p.

BATISTA, A. C. Incêndios florestais. Recife: Imprensa Universitária - UFRPE, 1990. 115 p.

BATISTA, A. C. Avaliação da queima controlada em povoamentos de Pinus taeda $L$. no norte do Paraná. 1995. 180f. Tese (Doutorado em Engenharia Florestal) - Setor de Ciências Agrárias, Universidade Federal do Paraná, Curitiba.

BEUTLING, A. Caracterização para modelagem de material combustível superficial em reflorestamento de Araucaria angustifolia (Bert.) O. Ktze. 2005. 113f. Dissertação (Mestrado em Ciências Florestais) - Universidade Federal do Paraná, Curitiba.

BROWN, J. K.; OBERHEU, R. D.; JOHNSTON, C. M. Handbook for inventorying surface fuels and biomass in the interior west. USDA Forest Service. Gen. Tech. Rep. INT-129, Ogden, UT, 1982.

BURGAN, R. E.; ROTHERMEL, R. C. BEHAVE: fire behavior prediction and fuel modeling system - fuel subsystem. Odgen, Intermountain Forest and Range Experiment Station, 1984. 126p.

CALDEIRA, M. V. W. Determinação de biomassa e nutrientes em uma Floresta Ombrófila Mista Montana em General Carneiro, Paraná. 2003. 176f. Tese (Doutorado em Engenharia Florestal) Universidade Federal do Paraná, Curitiba.

CHANDLER, C. et al. Fire in Forestry. John Wiley \& Sons, New York, 1983. $450 \mathrm{p}$.

DANTAS, T. V. P.; RIBEIRO, A. S. Caracterização da vegetação do Parque Nacional Serra de Itabaiana, Sergipe - Brasil. Biotemas, v. 23, p. 9-18, 2010.

FINNEY, M. A. Farsite: Fire Area SimulatorModel Development and Evaluation. USDA Forest Service, Intermountain Fire Sciences Laboratory, Missoula, MT, 1998, 52 p.

HÉLY, C. et al. Regional fuel load for two climatically contrasting years in southern Africa. Journal of geophysical research, v. 108, n. d13, p. $1-17,2003$.

MELO, L. A. M. N. et al. Modelagem do combustível florestal no Parque Nacional do Iguaçu, PR, Brasil. Floresta, Curitiba, PR, v. 36, n. 3, p. 415-424, 2006.

REGO, F. C.; BOTELHO, H. S. A técnica do fogo controlado. Universidade de Trás-os-Montes e Alto Douro, Vila Real, 1990. 124 p.

RIBEIRO, G. A.; SOARES, R. V. Caracterização do material combustível superficial e efeitos da queima controlada sobre sua redução em um povoamento de Eucalyptus viminalis. Cerne. Lavras, v.4, n.1, p. 58-72, 1998.

ROTHERMEL, R. C. A mathematical model for predicting fire spread in wildland fuels. Research Paper INT-115. Ogden, UT: U.S. Department of Agriculture, Forest Service, Intermountain Forest and Range Experiment Station, 1972. 40 p.

SCHROEDER, M. J.; BUCK, C. C. Fire weather. USDA Forest Service, Agriculture Handbook 360, 1970. 229 p.

SOARES， R. V. Determinação da quantidade 
de material combustível acumulado em e uso do fogo. Curitiba: FUPEF, 1985. plantios de Pinus spp. na região de Sacramento 213 p.

(MG). Floresta, Curitiba, v. 10, n. 1, SOARES, R. V.; BATISTA, A. C. Incêndios p. 48-62, 1979.

Florestais: controle, efeitos e uso do fogo. Curitiba, SOARES, R. V. Incêndios florestais: controle 2007.264 p. 